\title{
ВЛИЯНИЕ ЭЛЕКТРОННЫХ ДЕНЕГ НА ДЕНЕЖНО-КРЕДИТНУЮ СИСТЕМУ
}

\author{
(c) 2019 Пирогов Владислав Юрьевич \\ кандидат физико-математических наук, \\ доцент кафедры «Программирование и автоматизация бизнес процессов» \\ Шадринский государственный педагогический университет, Россия, Шадринск \\ E-mail: vladislav-133@yandex.ru \\ (c) 2019 Попова Екатерина Игоревна \\ кандидат экономических наук, \\ доцент кафедры «Программирование и автоматизация бизнес-процессов» \\ Шадринский государственный педагогический университет, Россия, Шадринск \\ E-mail:978073@mail.ru
}

В данной статье рассматриваются подходы влияния электронных денег на денежное обращение в современной информационной экономике. Проанализированы позиции экономистов по поводу влияния электронных денег на скорость обращения денег и на денежную массу.

Ключевые слова: электронные деньги, электронные платежные системы, денежное обращение, скорость обращения денег, денежная масса, денежная система, криптовалюта.

Электронные деньги уже давно вошли в современную жизнь людей и это не удивительно, поскольку в информационной экономике основным средством осуществления обмена становятся электронные деньги, которые обладают рядом преимуществ, таких, как экономия ресурсов (исключение печатания, транспортировки и т.д.), возможность контроля за денежными операциями, их отслеживание и предотвращение уклонений от налогов, быстрая оплата товара и услуг и т.п. В результате этого, возникают спорные вопросы о влиянии электронных денег на денежное обращение.

Ряд экономистов (Б. Эли, Е. Келли) считают, что электронные деньги не оказывают никакого влияния на денежную политику, т.к. они не отличаются от других существующих на сегодня форм денег. Другие же экономисты (М. Крюгер, М. Вудфорд) считают, что влияние электронных денег на денежную систему можно легко контролировать, используя традиционные механизмы денежно-кредитного регулирования, а именно с помощью таргетирования процентной ставки [4, с.236.].

В настоящее время, остается и дискуссионным вопрос о влиянии электронных денег на денежную массу, ряд экономистов считают, что широкое распространение электронных денег может способствовать вытеснению значительного объема наличных денежных средств Центрального банка, что приведет к искажению со- ставляющих денежной базы. Так, А. Берентсен в своих работах отмечал, что электронные деньги в принципе могут заменить наличные деньги, эмитируемые Центральным банком, но поскольку наличные деньги Центрального банка являются компонентами всех денежных агрегатов, то изменение в спросе на традиционные наличные деньги может воздействовать на все эти агрегаты. Однако наибольшее воздействие, по мнению А. Берентсена, будет оказано на денежный агрегат M1, который в большинстве стран включает в себя наличные деньги Центрального банка в обращении, дорожные чеки и депозиты до востребования. В других денежных агрегатах, прежде всего, в агрегатах M2 и M3, также будут происходить изменения, но по причине невысокого удельного веса в них наличных денег Центрального банка эти изменения будут не столь значительны [7].

Вопросами влияния электронных денег на показатели денежной массы и денежно-кредитное регулирование были рассмотрены и в работах отечественного экономиста Д.А. Кочергина. По его мнению, замещение наличных денег электронными может привести к определенному росту предложения банковских резервов и увеличению денежной массы в узком определении (M1). Влияние данного замещения будет эквивалентно операциям Центрального банка на открытом рынке, которые обеспечивают поступление дополнительных резервов. Измене- 
ния в объеме денежной массы будут зависеть от величины эмиссии электронных денег, институциональной стратегии и учетной политики, реализуемых органами денежно-кредитного регулирования, а также выбранных тактических целей денежно-кредитной политики. Можно ожидать, что рост денежной массы в результате эмиссии электронных денег будет неизбежным, но его темпы будут плавными и контролируемыми [4, с.256].

Таким образом, влияние эмиссии электронных денег на денежную массу является неоднозначным и зависит от ряда дополнительных предложений, например, включения или не включения электронных денег в определение понятия денежной массы. Если учитывать объём электронных денег при расчете денежной массы, то при обмене электронных денег, выпущенных банком, на наличные деньги клиента произойдёт уменьшение агрегата М0 и соответствующее увеличение депозитов. В данном случае агрегат M1 увеличится из-за расширения депозитов, в результате денежная масса возрастет. Однако, если со стороны Центрального банка будут введены обязательные резервные требования на объём эмитированных электронных денег, расширение депозитов будет меньше, а при стопроцентной ставке резервирования, которую предлагают установить некоторые экономисты, вообще не произойдёт, и денежная масса не изменится. Если даже и произойдет увеличение роста денежной массы, темпы его, по мнению Д.А. Кочергина, можно контролировать [3].

Важной характеристикой денежного обращения является скорость обращения денег.

Поскольку использование информационных технологий в платежных системах способствует сокращению времени проведения платежей, тем самым встает вопрос о зависимости сокращения времени проведения платежа и скоростью обращения денег, а также увеличением денежной массы [1].

Ряд экономистов утверждают, что использование электронных расчетов является одним из факторов инфляции и способствует увеличению денежной массы. Одно из таких утверждений: «Одним из факторов, влияющим на скорость обращения денег, является использование электронных денег в расчетах. В связи с тем, что скорость обращения денег обратно пропорциональна количеству денег в обращении, то ускорение их оборачиваемости означает рост денеж- ной массы. Увеличение денежной массы при том же объеме товаров и услуг на рынке ведет к обесценению денег, т.е. в конечном итоге, является одним из факторов инфляционного процесса» [4, c.38].

Утверждение о том, что удобство и быстрота расчетов через электронные платежные системы приведет к увеличению интенсивности движения денег, как отмечает Л. Наумовский «При постоянстве массы денег и количества товаров увеличение скорости обращения денег приведет к повышению общего уровня цен, т.е. к инфляции» [6, с.30] Также на наш взгляд, лишено аргументов экономического анализа.

Скорость обращения денег определяется числом оборотов денежной единицы, а сам оборот представляет собой меновые операции (т.е. Т-Д, Д-Т), из этого следует, что применение электронных расчетов способствует увеличению меновых операций. Тем не менее, короткое время перевода денег не является средством мотивации для покупателя к приобретению большего количества товаров и услуг. Из-за достаточного быстрого поступления денежных средств на счет, меновые операции не будут совершаться сами по себе. Современные платежные системы предоставляют свои клиентам высокоскоростные услуги, соответственно осуществление переводов денежных средств будет происходить с такой интенсивностью, с которой это требует финансовая и хозяйственная деятельность экономических субъектов. Спрос на товары будет зависть от многих факторов: рост доходов населения, прибыли фирм, увеличение рабочих мест, объемов налоговых поступлений и т.п.

Скорость обращения денег это величина переменная и периодичная, ее изменчивость зависит от многих факторов, таких, как рост богатства общества, численности населения, изменения процентной ставки, развитие кредитов, цикличности колебания торговли, обесценения денежной единицы в условиях инфляции, и др [5].

Предложения по поводу влияния электронных денег на скорость денежного обращения, которое может привезти к увеличению денежной массы, также являются весьма неоднозначными, потому как система расчетов не существует сама по себе: деньги не станут обращаться без осуществления сделок. Следовательно, положительный результат от повышения эффективности расчетов, будет выше, чем предполагаемый 
риск инфляции. Кроме того, монетарные институты стран обладают рядом эффективных экономических рычагов, ограничивающих или прекращающих предполагаемые негативные последствия использования электронных денег для сохранения стабильности экономики.

Следует отметить, что в России отсутствуют четкие правила регулирования операций с электронными деньгами, что является основным препятствием к широкому распространению электронных денег в денежном обороте России. Основным законодательным актом, регулирующим вопросы функционирования и перевода электронных денежных средств в России, является Ф3 «О Национальной платежной системе».

В настоящее время во многих странах все большую популярность приобретают криптовалюты. На сегодняшний день насчитывается более тысячи разновидностей криптовалют, многие из них ничем не обеспечены, но особой популярностью пользуется самая первая криптовалюта - биткоин. Но, если сравнивать криптовалюту с электронными деньгами, то, по нашему мнению, ее можно лишь наполовину отнести к электронным деньгам, так как она не выполняет все функции электронных денег: она не является общепринятым средством обращения, не является единицей счета и т.п. Криптовалюты являются деньгами лишь для некоторой группы людей. Это своего рода сложные математические действия, алгоритмы, которые позволяют решать задачи, причем решение каждой новой задачи рождает определенный цифровой код, что и является криптомонетой. Причем следует отметить, что это децентрализованная ва- люта, которая не имеет одного эмитента, т.е. все пользователи и каждый участник, который участвует в эмиссии криптовалюты, имеют полный доступ к информации всего блока [1]. Другими словами, создание криптовалют и связанные с ними операции имеют открытый исходный код, контролируются по коду и опираются на одноранговые сети. Не существует единого органа, способного влиять на криптовалюту.

В России к эмиссии электронных денег и внедрению их в денежный оборот не готовы пока не только банки, но и само государство. Кроме того, как отмечает Д.А. Кочергин, в связи с внедрением электронных денег возникнут разногласия с центральными эмиссионными банками по следующим вопросам:

- разрешение эмиссии электронных денег и определение круга эмитентов;

- организация регулирования и обращения электронных денег;

- решение проблемы возникающих рисков в системах электронных денег [3].

Остро встает проблема и мошенничества с электронными деньгами, т.е. электронные деньги могут быть с целью различных мошеннических схем: отмывание «грязных денег», подделка электронных денег, уклонение от налогов, организация азартных игр и т.п. Все эти и многие другие моменты не дают широкого распространения электронных денег в денежном обороте страны. Вполне вероятно, что скоро электронные деньги появятся в денежном обороте многих стран, но пока полный переход на электронные деньги не представляется возможным.

\section{Библиографический список}

1. Горшков А.В. Попова Е.И. Трансформационные изменения сферы денежного обращения с переходом к информационной экономике / А.В. Горшков, Е.И. Попова // Вестник Челябинского государственного университета. Экономика - Челябинск. - 2018 - № 7(417). - С. 49-55.

2. Жуков, Е. Ф. Общая теория денег и кредита [Текст]: учебник / Е.Ф. Жуков [и др.].- 2-е изд., перераб. и доп.М.: ЮНИТИ, 2002.- 423 с. 46

3. очергин, Д.А. Электронные деньги [Текст] / Д.А. Кочергин.- М.: Маркет ДС, ЦИПСиР, 2009. - 490 с.

4. Красноперов, С.В. Изменение границ денежного обращения -индикатор дефицита денег в экономике России [Текст] / С.В. Красноперов // Финансы и кредит. - 2000.- № 7.- С. 76-81.

5. Крылова, О.В. Особенности платежных систем на основе пластиковых карточек [Текст] / О.В. Крылова // Банковские технологии. - 2004.- № 12.- С. 53-55.

6. Наумовский, Л. Перспективы развития системы электронных карточных платежей [Текст] / Л. Наумовский.- М.: CEMEA-MemCom, 2005.- 113 с.

7. Berentsen A/ Digital money, liguidity and monetary policy // Ferst Monday. - 1997. - vol.2._ number 7. 